\title{
Estrogenic Effects of Euphorbia hirta L. Extract in Ovariectomized Rats
}

\author{
Wilawan Promprom*, Wannachai Chatan
}

\section{Wilawan Promprom*, Wannachai Chatan}

\author{
Department of Biology, Faculty of \\ Science, Mahasarakham University, \\ THAILAND. \\ Correspondence \\ Dr. Wilawan Promprom \\ Department of Biology, Faculty of \\ Science, Mahasarakham University, \\ THAILAND. \\ Phone +66 56121384; \\ Fax: +6643754245 \\ E-mail: wipromprom@gmail.com

\section{History} \\ - Submission Date: 07-09-2017. \\ - Review completed: 21-10-2017; \\ - Accepted Date: 10-11-2017.
}

DOI : 10.5530/pj.2018.3.71

Article Available online http://www.phcogj.com/v10/i3

\section{Copyright}

(c) 2018 Phcog.Net. This is an openaccess article distributed under the terms of the Creative Commons Attribution 4.0 International license.

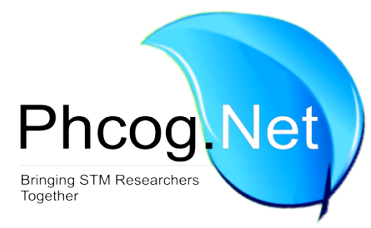

\begin{abstract}
Context: Euphorbia hirta L. has been wildly used for its health benefits. It has been used as a decoction and to treat diarrhea, peptic ulcers, menstrual problems and venereal diseases. Aims: The study aims to investigate the estrogenic effects of E. hirta on ovariectomized (OVX) rats. Methods: The ovariectomized rats were divided into four groups, including those that received the vehicle (1\% v/v Tween 80, p.o.), $17 \beta$-estradiol at a dose of $0.01 \mathrm{mg} / \mathrm{kg} \mathrm{B.W}$. and the ethanolic extract of E. hirta at the doses of 100 and $500 \mathrm{mg} / \mathrm{kg} \mathrm{B.W}$. These were administered daily for 14 days. Estrogenic activity was determined by analyzing the body, vaginal and uterine weight as well as the uterine and vaginal histopathology characteristics of the estrogen-induced response. Results: At the dose of $500 \mathrm{mg} / \mathrm{kg} \mathrm{B.W.,} \mathrm{the} \mathrm{plant} \mathrm{extract} \mathrm{produced}$ a significant increase in vaginal weight when compared with the ovariectomized rats, a slightly increase in the uterine weight and could induce hyperplastic epithelium and endometrial thickness of the vagina. Conclusion: The data in this work suggests that the plant crude extract showed weak estrogenic effects in ovariectomized rats and could be useful for health benefits for vagina atrophy of females during the menopause.

Key words: Euphorbia hirta L., Estrogenic, Ovariectomized rats, Uterus, Vagina.
\end{abstract}

\section{INTRODUCTION}

Reproductive disorders have always been critical issues on uterine and vaginal tissue for women during the menopause, and the decrease of estrogen in older women is one cause of these problems. Estrogen plays an important role in the growth, differentiation and function of many target tissues, including the tissues of the female and male reproductive systems. ${ }^{1}$ Gynecologists and obstetricians recognize the fundamental importance of estrogen in the pathogenesis of multiple disorders of the female reproductive system. One of the treatments for reproductive tissue disorders in females is the use of synthetic estrogen, but it causes some side effects, such as the risk of hormone-dependent cancers, particularly breast cancer and endometrial cancer. ${ }^{2,3}$ As well as urinary incontinence. ${ }^{4}$ It was found that natural compounds from certain plants, called phytoestrogens, could be used for the management of menopausal symptoms and they have few side effects. ${ }^{5}$ Thus, phytoestrogen is an alternative treatment that is currently popular and used in many countries.

Euphorbia hirta L., a plant in the family Euphorbiaceae, is a very common herb in pan-tropic and partly subtropic regions worldwide, including Africa, Australia, China, India, Malaysia and the Philippines, etc., ${ }^{6}$ and naturally distributed in all floristic region of Thailand. ${ }^{7}$ E. hirta is known to contain flavonoids, polyphenols, tannins and $\beta$-Sitosterol. ${ }^{8}$
People in Thailand use E. hirta as a diuretic drug, antitussive, anti-asthmatic, antiepileptic, to promote lactation, antidysenteric, infusion and to relieve pain and fever..$^{10}$ However, E. hirta still lacks scientific data to clarify its estrogenic properties. Therefore, the objectives of the study were to evaluate the estrogenic activity of the shoot extract of $E$. hirta by observing the uterine and vaginal tissues and weights as well as the body weight in ovariectomized rats as an animal model of the menopause.

\section{MATERIALS AND METHODS}

\section{Plant collection and preparation of extract}

The shoots of E. hirta were collected from the campus of Mahasarakham University, Mahasarakham, Thailand from February to March. The voucher specimen (W.Chatan 2413) was identified and confirmed by the sec author and deposited in the Natural Medicinal Mushroom Museum (MSUT), Mahasarakham University, Thailand for future reference. The shoots were cleaned, air dried, powered and subjected to macerate extraction with ethanol. The extract was filtered through filter paper, evaporated in a rotary evaporator, dried by a lyophilizer and kept at $-20^{\circ} \mathrm{C}$ until use. 


\section{Animals and experimental procedures}

Animals

Twenty-four female Wistar rats (200-230g) were used in this study and maintained in accordance with the guidelines of the Committee on the Care and Use of Laboratory Animal Resources, National Research Council, Thailand. The experiments performed on rats were conducted in accordance with the advice of the Institutional Animal Care and Use Committee of Maharsarakham University (proposal number: 0002/2013). The animals were kept in polypropylene cages under standard conditions (12-h light and 12-h dark cycles; $25 \pm 2{ }^{\circ} \mathrm{C}$ temperature) and had free access to a commercial pellet diet and water ad libitum.

\section{Bilateral Ovariectomy Procedure}

The ovariectomy (OVX) procedure was performed by anesthetizing the rats with isoflurane. After placing the animal in the right lateral recumbency on a water jacketed heating pad to the maintain body temperature, the flank region of the anesthetized rat was clipped and aseptically prepared. An incision was made on the animal's right flank. The right ovary was located, and a circumferential suture was placed around the ovarian artery and vein. The right ovary was removed just distal to the suture. The same procedure was repeated to remove the left ovary. ${ }^{11}$

\section{Experimental design}

Estrogenic activity of the plant extract was assessed in bilaterally ovariectomized rats. The parameters of assessment were uterine and vaginal wet weight and histology. The ovariectomized rats were divided into four groups, and each group contained six rats. All the rats received their treatment for 14 days. Group I (control) received $1 \mathrm{ml}$ of $1 \%$ (v/v) Tween 80 suspension, Group II (standard) received $17 \beta$-estradiol at a dose of $0.01 \mathrm{mg} / \mathrm{kg}$ B.W. and Group III and Group IV (test) received $1 \mathrm{ml}$ of plant extract at the doses of 100 and $500 \mathrm{mg} / \mathrm{Kg} \mathrm{B.W.,} \mathrm{respectively.}$

\section{Body weight and relative organ weight}

The rats were humanely sacrificed at the end of the experiment by $\mathrm{CO}_{2}$ asphyxia. All connective tissues were removed prior to wet weight recording. Body, horns of uteri and vaginal weights were recorded. Relative uterine and vaginal weights were calculated by the following formula. ${ }^{12}$

$$
\text { Relative Organ Weight }=\frac{\text { Organ weight }(\mathrm{g}) \times 100}{\text { Body weight of rat on sacrifice day }(\mathrm{g})}
$$

\section{Histology}

Each the uterus and vagina were kept in $10 \%$ neutral buffer formalin for $24 \mathrm{~h}$ for fixation. Then they were dehydrated in a series of ascending gradients of ethyl alcohol (70\%, 80\%, 95\% and 100\%). The samples were finally embedded in paraffin wax. Serial sections of $5 \mu \mathrm{m}$ were stained with hematoxylin and eosin and then examined by microscopy. ${ }^{13}$

\section{Statistical Analysis}

The values are expressed as mean $\pm \operatorname{SEM}$ ( $\mathrm{n}=6$ for each group). ${ }^{\star} \mathrm{P}$ values $<0.05$ were considered significant using a one-way ANOVA followed by Duncan's multiple comparison tests.

\section{RESULTS}

\section{Body weight and relative organ weight}

Fourteen days after ovariectomy, the means of the initial body weights were not different among the groups. At the end of the experiment, the results showed that the bilateral OVX enhancement sustained increases in the final body weight. The standard drug $17 \beta$-estradiol and the ethanolic extract of E. hirta (500 mg/kg B.W.) showed statistically significant $(\mathrm{p}<0.05)$ decreases in body weight, when compared to OVX Table 1.

The relative uterine weight of the standard drug $17 \beta$-estradiol significantly increased $(0.19 \pm 0.01 \%)$ when compared with the ovariectomized rats $(\mathrm{p}<0.05)$. The relative vaginal weight of the ovariectomized rats was significantly decreased compared with the standard drug $17 \beta$-estradiol and the ethanolic extract of E. hirta (500 mg/kg B.W.) Table 1.

\section{Effect of E. hirta on morphology of uterus and vagina}

Figure 1 shows the microscopic preparations of the representative uteri taken from one animal per treatment group. The uterine sections of the ovariectomized rats' endometrium were dense and thin Figure 1A. The histological features demonstrated typical atrophic features with the thinning of the uterine endometrial layer. This layer contained atrophied uterine glands and poor vascularity, which were covered by low cuboidal epithelial. The endometrium was composed of cuboidal inactive cells. The oral administration of $17 \beta$-estradiol stimulated the size and structure of all uteri as illustrated by an increase in endometrial thickness, well developed uterine gland and more vascularity. The bulky epithelial layer was well developed, as indicated by the columnar cell type Figure 1B. While, the E. hirta (100 mg/kg B.W.) extract did not make a significant change to the endometrial proliferation Figure 1C. For the E. hirta (500 mg/kg B.W.) extract, it caused a slight increase in the endometrial proliferation, but no pathology signs were detected Figure 1D.

Figure 2 shows the microscopic preparations of the representative vagina taken from one animal per treatment group. The atrophic vaginal epithelium was observed in ovariectomized rats. Normally this layer consisted of one to two shriveled cuboidal or flattened squamous cell types with a diminutive mucous cell Figure 2A. The result showed that the groups treated with the $17 \beta$-estradiol displayed a typical squamous multilayered epithelium Figure $2 \mathrm{~B}$. While the number of layers did not differ from the ovariectomized rats, and cornification could not be found in the E. hirta $100 \mathrm{mg} / \mathrm{kg}$ B.W. treatment Figure 2C. For the group treated with the E. hirta $500 \mathrm{mg} / \mathrm{kg}$ B.W. extract, the epithelium thickness was slightly enlarged Figure 2D.

\section{DISCUSSION}

Table1: Body weight and organ weight.

\begin{tabular}{ccccc}
\hline Treatment group & \multicolumn{2}{c}{ Body weight } & \multicolumn{2}{c}{$\begin{array}{c}\text { Relative organ weight } \\
\text { (g/100g body weight) }\end{array}$} \\
\cline { 2 - 5 } & Initial & Final & Uterus & Vagina \\
\hline OVX & $226.67 \pm 2.10$ & $268.33 \pm 1.66$ & $0.05 .33 \pm 0.00$ & $0.06 .50 \pm 0.00$ \\
$17 \beta$-estradiol & $221.67 \pm 1.66$ & $242.50 \pm 5.28^{*}$ & $0.19 .50 \pm 0.01^{\star}$ & $0.13 .85 \pm 0.02^{\star}$ \\
$100 \mathrm{mg} / \mathrm{kg}$ E. hirta & $229.17 \pm 3.96$ & $275.00 \pm 5.83$ & $0.05 .86 \pm 0.13$ & $0.05 .50 \pm 0.00$ \\
$500 \mathrm{mg} / \mathrm{kg}$ E. hirta & $220.83 \pm 3.27$ & $250.00 \pm 2.23^{*}$ & $0.06 .31 \pm 0.20$ & $0.11 .78 \pm 0.12^{\star}$ \\
\hline
\end{tabular}

${ }^{*}$ Means within a column with different letters are significantly different $(\mathrm{p}<0.05)$ 

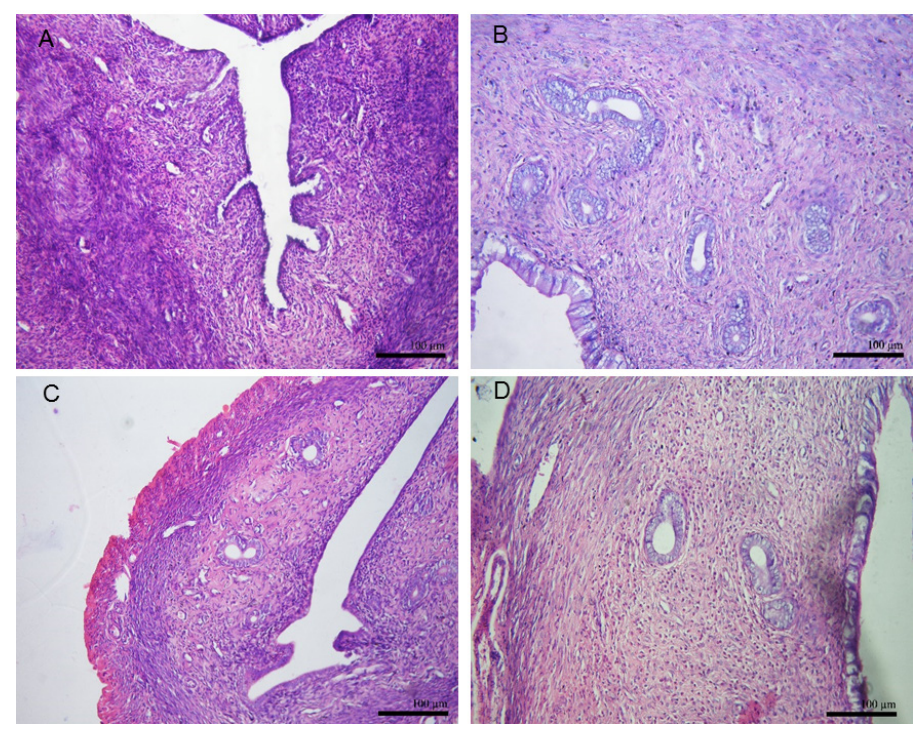

Figure 1: Representative photomicrographs of uterine histology. $\mathrm{A}=$ Ovariectomized rats; $B=17 \beta$-estradiol $(0.01 \mathrm{mg} / \mathrm{kg}$ B.W. $) ; C=E$. hirta $(100 \mathrm{mg} / \mathrm{kg}$ B.W.); $\mathrm{D}=E$. hirta $(500 \mathrm{mg} / \mathrm{kg}$ B.W.). Magnification of all pictures is $200 \mathrm{x}$.

During the reproductive cycle, the uterus and vagina undergo physiological changes under the influence of ovarian hormones, such as estrogen. ${ }^{14}$ these changes include the induction of uterine growth, uterine endometrial proliferation and vaginal keratinization and cornification. In the case of ovariectomy, the reproductive cycle stops, and estrogen is no longer produced. Without estrogen, the uterus and vagina undergo atrophy and the process of vaginal keratinization and cornification can no longer be observed. These symptoms relate to serious problems in postmenopausal women, which leads to a decrease in their life quality. However, administration of estrogenic substances to ovariectomized rats helps prevent atrophic changes in the organs and stimulates the proliferative changes in the uterine endometrium and processes in the vaginal keratinization and cornification. ${ }^{15}$

In the present study, the administration of estrogenic substances, such as $17 \beta$-estradiol, clearly replaced the lack of natural estrogen because of ovariectomy. We evaluated the potential of simultaneously dosing E. hirta to mitigate this effect; however, no activity was observed. Therefore, these data suggest that E. hirta had no effect on the uterus. Interestingly, we found that the ethanolic extract of E. hirta $(500 \mathrm{mg} / \mathrm{kg})$ increased the vaginal weight and epithelium in ovariectomized rats. Thus, the plant extract can be attributed to its estrogenic activity.

Previous studies conducted on the shoots of E. hirta indicated the presence of flavonoids, steroids and phenols. ${ }^{16}$ Flavonoids are euphobianin, leucocyanidol, camphol, quercitrin and quercitol. ${ }^{17,18}$ Polyphenols are Gallic acid, myricitrin, 3,4-di-o-galloylquinic acid, 2,4,6-tri-O-galloylD-glucose and 1,2,3,4,6-penta -O-galloyl- $\beta$-D-glucose. ${ }^{19,20}$ Tannins are euphorbins A, B, C, D, E. ${ }^{21}$ Triterpenes and phytosterols are $\beta$-Amyrin, 24 -methylenecycloartenol and $\beta$-Sitosterol. ${ }^{22}$ In addition, flavonoids, phenols and $\beta$-Sitosterol are known to possess estrogenic activity. ${ }^{23,24}$ Thus, the estrogenic activity shown by the extract of $E$. hirta can be attributed to the presence of flavonoid, $\beta$-Sitosterol and phenol compounds.

\section{CONCLUSION}

In conclusion, we have shown that the E. hirta extract has in vivo estrogenic effects in the rat vagina but not in the uterus. In addition, E. hirta did not produce any additive dose effects on estrogenic activity when administered with $17 \beta$-estradiol.
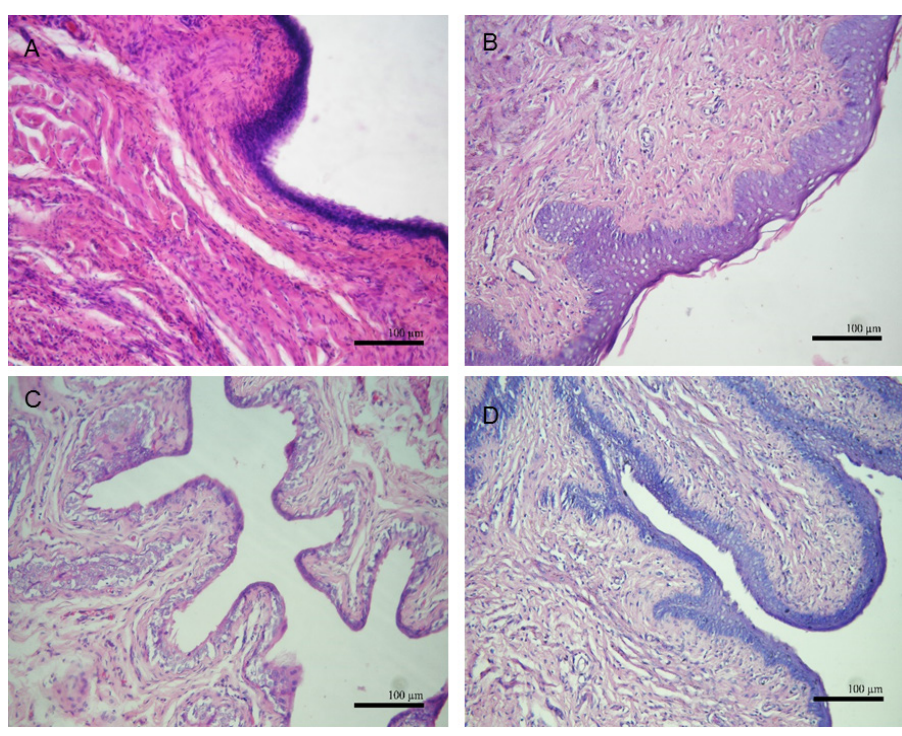

Figure 2: Representative photomicrographs of vagina histology. $A=$ Ovariectomized rats; $B=17 \beta$-estradiol (0.01 mg/kg B.W.); $C=$ E. hirta $(100 \mathrm{mg} / \mathrm{kg}$ B.W.); $\mathrm{D}=E$. hirta (500 mg/kg B.W.). Magnification of all pictures is 200x.

\section{ACKNOWLEDGEMENT}

We gratefully acknowledge Mahasarakham University 2013, Thailand for financial support. Thanks for linguistic advice from Dr. Jolyon Dodgson, Faculty of Science, Mahasarakham University.

\section{CONFLICT OF INTEREST}

None.

\section{ABBREVIATIONS USED}

OVX: Ovariectomized rats; BW: Body weight

\section{REFERENCES}

1. Tsai MJ, Clark JH, SchraderWT, O'Malley BW. Mechanisms of action of hormones that act as transcription regulatory factors. In Williams RD, Wilson JD, Williams Textbook of Endocrinology, $9^{\text {th }}$ edition, chapter 4. 1998:55-94.

2. Barnabei VM, Grady D, Stovall DW, Cayley JA, Lin F, Stuenkel CA, et al. Menopausal symptoms in older women and the effects of treatment with hormone therapy. Obstet Gynecol. 2002;100(6):1209-18.

3. Zhang DW, Wang ZL, Qi W, Zhao GY. The effects of Cordyceps sinensis phytoestrogen on estrogen deficiency-induced osteoporosis in Ovariectomized rats. BMC Complement Altern Med. 2014;14(1):484.

4. Grodstein F, Lifford K, Resnick NM, Curhan GC. Postmenopausal hormone therapy and risk of developing urinary incontinence. Obstet. Gynecol. 2004;103(2):254-60

5. Glazier MG, Bowman MA. A review of the evidence for the use of phytoestrogen for traditional estrogen replacement therapy. Arch Intern Med. 2001;161(9):1161-72

6. Huang L, Chen S, Yang M. Euphorbia hirta (Feiyangcao): A review on its ethnopharmacology, phytochemistry and pharmacology. J. Med. Plants Res. 2012 6(39):5176-85

7. Chayamarit K, Welzen PC. Euphorbiaceae, In: Santisuk, T. and Larsen, K. (Eds.) Flora of Thailand. Prachachon, Bangkok. 2005;8(1):1-303.

8. Chitra M, Muga V, Dhanarasu S, Al-hazimi AM. Screening of Phytochemical and In vitro activity of Euphorbia hirta L. J Chem Pharm Res. 2011;3(6):110-4

9. Chuakul W. Taxonomy of Medicinal Plants. Varanont Enterprise, Bangkok. 2005;1-485pp.

10. Chuakul W, Salalamp P, Paonin W, Temsiririrkkul R, Clayton T. Medicinal Plants in Thailand, Amarin Printing and Publishing Public, Bangkok. 1997;2:1-248.

11. Promprom W. Estrogenic activity of Pomegranate (Punica granatum L.) extract in ovaiectomized rats. Doctoral dissertation, Suranaree University of Technology. Thailand. 2009;211pp.

12. Aniagu SO, Nwinyi FC, Akumka DD, Ajoku GA, Dzarma S, Izebe KS, et al. Toxicity studies in rats fed nature cure bitters. Afr J Biotechnol. 2005;4(1):72-8. 
13. Parhizkar S, Latiff LA, Rahman SA, Dollah MA. Evaluation of estrogen-like activity of Nigella sativa in ovariectomized rats. Afr J Pharm Pharmacol. 2011;5(8):1006-11.

14. Prakash AO, Mathur R. Biochemical changes in the rat uterine tissue following Embelia ribes extracts. Indian J Pharmacol. 1997;11(2):127-34.

15. Williamson EM, Okpako DT. Endocrine activity: antifertility and sex hormones. In: Evans, F.J. (Ed.), Pharmacological Methods in Phyto therapy Research Selection. Preparation and Pharmacological Evaluation of Plant Material, John Wiley and Sons. New York. 1996;1:191-216.

16. Chitra M, Muga V, Dhanarasu S, Al-hazim AM. Screening of Phytochemical and In vitro activity of Euphobia hirta L. J Chem Pharm Res. 2011;3(6):110-4.

17. Blanc P, Bertrand P, Sannes DS. Flavonoids of Euphorbia hirta. Plantes Med. Phytoher. 1972;6:106-9

18. Aqil M, Khan IZ. Euphorbianin, a new flavonol glycoside from Euphorbia hirta Linn. Global Journal of Pure and applied science. 1999;5(3):371-4.

\section{GRAPHICAL ABSTRACT}

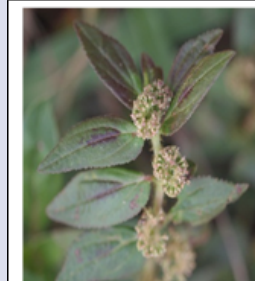

19. Chen L. Polyphenols from leaves of Euphorbia hirta Linn. Zhongguo Zhong Yao Za Zhi. 1991;16(1):38-9.

20. Yoshida T, Chen L. Tannins and related polyphenols of euphorbiaceous plant IV Euphorbins $A$ and $B$, novel dimeric dehydroellagitannins from Euphorbia hirta $L$. Chemical and Pharmaceutical bulletin. 1988;36(8):2940-9.

21. Yoshida T, Namba O, Okuda T. Hydrolysable tannin oligomers from Euphorbiaceae. Tennen Yuki Kagobutsu Toronkai Koen Yoshishu. 1989;31:601.

22. Martinz V. Antiinflammatory compounds from the $\mathrm{n}$ hexane extract of Euphorbia hirta. Reviews sociedad Quimica De mexio. 1999;43(3-4):103.

23. Murad F, Jeffrey AK. Estrogens and progestins in: Alfred GG, Theodore WR, Alan S. N, Palmer T. (Eds.), Goodman and Gilman's The Pharmacological Basis of Therapeutics. Maxwell Macmillan Pergamon Publishing Corp, New York. 2(8) 1384 .

24. Kuiper GG, Lemmen JG, Carlsson BO. Interaction of estrogenic chemicals and phytoestrogens with estrogen receptor $\beta$. Endocrinology. 1998;139(10):4252-63.
At the dose of $500 \mathrm{mg} / \mathrm{kg}$ B.W.., the plant extract induce hyperplas tic epithelium and endometrial thickness of the vagina.

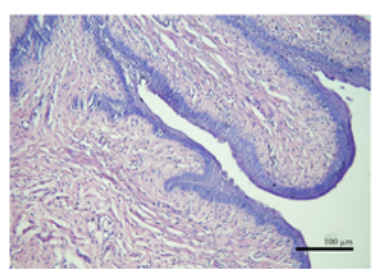



\section{SUMMARY}

- Euphorbia hirta L. has been wildly used for its health benefits. The shoots of E. hirta were collected from the campus of Mahasarakham University, Mahasarakham, Thailand.

- The ethnolic extract of E. hirta $(500 \mathrm{mg} / \mathrm{kg} \mathrm{B.W.)} \mathrm{showed} \mathrm{statistically} \mathrm{signifi-}$ cant $(p<0.05)$ decreases in body weight, when compared to Ovariectomized (OVX).

- At the dose of $500 \mathrm{mg} / \mathrm{kg}$ B.W., the plant extract produced a significant increase in vaginal weight when compared with the ovariectomized rats, and could induce hyperplastic epithelium and endometrial thickness of vagina.

\section{ABOUT AUTHORS}

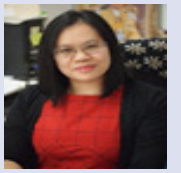

Wilawan Promprom: Ph.D: Presently, working as Assistant Professor in Department of Biology, Faculty of Science, Mahasarakham University, THAILAND. Her research focused on chemical composition and antioxidant of medicinal plants, estrogenic activity and anti-diabetes mellitus plants.

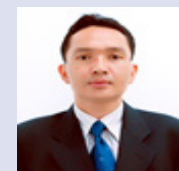

Wannachai Chatan: Ph.D: Assistant Professor in Department of Biology, Faculty of Science, Mahasarakham University, THAILAND. His research focused on plant taxonomy and ethnobotany.

Cite this article: Promprom W and Chatan W. Estrogenic effects of Euphorbia hirta L. Extract in Ovariectomized rats. Pharmacog J. 2018;10(3):435-38. 